\title{
Investigation of the Growth Kinetics of Tetra-n-butylammonium Bromide Hydrate Formation in Small Spaces
}

Shi, Meng; Lang, Xuemei; Wang, Yanhong; von Solms, Nicolas; Fan, Shuanshi

Published in:

Energy and Fuels

Link to article, DOI:

10.1021/acs.energyfuels.8b04042

Publication date:

2019

Document Version

Peer reviewed version

Link back to DTU Orbit

Citation (APA):

Shi, M., Lang, X., Wang, Y., von Solms, N., \& Fan, S. (2019). Investigation of the Growth Kinetics of Tetra-nbutylammonium Bromide Hydrate Formation in Small Spaces. Energy and Fuels, 33(4), 3473-3482.

https://doi.org/10.1021/acs.energyfuels.8b04042

\section{General rights}

Copyright and moral rights for the publications made accessible in the public portal are retained by the authors and/or other copyright owners and it is a condition of accessing publications that users recognise and abide by the legal requirements associated with these rights.

- Users may download and print one copy of any publication from the public portal for the purpose of private study or research.

- You may not further distribute the material or use it for any profit-making activity or commercial gain

- You may freely distribute the URL identifying the publication in the public portal 


\section{Final accepted manuscript:}

Shi, M., Lang, X., Wang, Y., von Solms, N., \& Fan, S. (Accepted/In press). Investigation of the Growth Kinetics of Tetra-n-butylammonium Bromide Hydrate Formation in Small Spaces.

Energy and Fuels. https://doi.org/10.1021/acs.energyfuels.8b04042

\section{Investigation of growth kinetics of tetra-n-butylammonium bromide hydrate formation in small spaces}

Meng Shi; Xuemei Lang; Yanhong Wang; Nicolas von Solmst; Shuanshi Fan*;

School of Chemistry and Chemical Engineering, South China University of Technology, Guangzhou 510640, China $\digamma$ Center for Energy Resource Engineering, Department of Chemical and Biochemical Engineering, Technical University of Denmark, 2800 Kgs. Lyngby, Denmark

* Corresponding Author: Shuanshi Fan, Tel: + 86-20-22236581, E-mail:ssfan@scut.edu.cn 


\begin{abstract}
Kinetics of tetra- $n$-butylammonium bromide (TBAB) hydrate formation orientated within the space of a small dimension tube is investigated through microscopic experiments in the temperature range $-5.5{ }^{\circ} \mathrm{C}$ to $-9.7{ }^{\circ} \mathrm{C}$. Based on the experimental data, a kinetic model in small dimensional space is proposed to describe formation process. Hydrate crystals are observed uniformly growing in small dimensional space. The experimental results show that the nucleation time of $\mathrm{TBAB}$ hydrate increases from $9 \mathrm{~min}$ to $25 \mathrm{~min}$ and linear growth rate decreases from $16.36 \mu \mathrm{m} / \mathrm{s}$ to $9.66 \mu \mathrm{m} / \mathrm{s}$ with increasing temperature. Crystal morphologies show that the tube wall has less effect on the inner crystal growth, when the temperature is lower. Furthermore, the number of nucleation sites increase under even lower temperature. The varying degree of brightness of the crystals indicates that there is a variation of facets of hydrate crystal formed at different temperatures. Hydrate crystals under lower temperature exhibit more growth points and the linear growth rate of crystals in tube is larger than that in bulk because of heat-transfer effects. A negative activation energy during hydrate formation in this study is obtained according to kinetic equation to be -58.27 $\mathrm{kJ} / \mathrm{mol}$.
\end{abstract}

Keywords: TBAB hydrate, growth kinetics, small dimensional space, activation energy 


\section{Introduction}

Clathrate hydrate crystals consist of cages composed of water molecules, stabilized by other, small, molecules trapped inside the cages as guest molecules ${ }^{1-}$ ${ }^{4}$. If a guest molecule is too large to fit in a cage, semi-clathrates may be formed by connecting ionic guests and water molecules as hosts and with the cation embedded into the cages as a guest. Tetra-n-butylammonium bromide (TBAB) is an example of a semi-clathrate hydrate former, where guest gas molecules are not required to form a hydrate structure, as is the case for normal clathrate hydrates ${ }^{5}$. The formation conditions of TBAB hydrate are mild and they can form at atmospheric pressure ${ }^{6}$.

In recent years, TBAB hydrate has shown many advantages for various applications, such as gas storage/separation technologies, refrigeration technologies, etc ${ }^{7-11}$. Recently, TBAB semi-clathrate hydrate slurry has been proposed as a promising cold energy storage medium in air-conditioning systems for high cold storage capacity compared to other medium such as water or ice slurry ${ }^{12-15}$. TBAB hydrate usually could not generated at equilibrium conditions, therefore, a well-established research on TBAB hydrate at different subcooling is of necessary for practical applications. Also, TBAB can act as an additive to considerably reduce the equilibrium pressure of gas hydrates commonly utilized in promoting the formation of gas hydrate and in separating gas mixture ${ }^{16-20}$. The study of Lee et $\mathrm{al}^{21}$ showed that presence of TBAB TBAB at weight percentage of ( 0.05 to 0.6 ) caused the $H-L_{w}-V$ equilibrium line of the $\mathrm{N}_{2}+$ TBAB semiclathrates to be greatly shifted to higher temperature and lower pressure regions when compared to that of pure $\mathrm{N}_{2}$ hydrate. They concluded that the highest stabilization effect was at mass fraction of 0.4 . In order remove hydrogen sulfide from biogas, Kamata et al ${ }^{16}$ confirmed that $>90 \%$ of the $\mathrm{H}_{2} \mathrm{~S}$ in the initial vapor phase was separated from biogas by incorporating into the $10 \mathrm{wt} \%$ TBAB solution and found TBAB hydrate was an effective and economical desulfurization medium. These applications are the direct result of the formation of TBAB hydrate. Thus, nucleation and growth characteristics of TBAB semi-clathrate hydrate is of vital importance in studies involving TBAB. The morphology of TBAB hydrate is also one of study factors should be focused on. The investigations on TBAB hydrate growth behavior are still limited although some progress has been made during the past few years ${ }^{22-24}$.

Over the years, studies of TBAB hydrate kinetics are mainly concerned with bulk systems, e.g. stainless vessel, glass tube $\mathrm{e}^{25-33}$. There is little literature focused on hydrate growth in small dimensional spaces. However, in many cases hydrate formation occurs within porous media, pores in packing materials, 
micro-channels of heat transfer, valves for gas pipelines or gaps in transfer equipment, in which the space for hydrate growth is limited. The mechanism of hydrate growth in small dimensional spaces is unclear, making this a natural and important aspect to investigate. There are difficulties involved in investigating hydrate growth properties during hydrate formation in pore-sized spaces, compared with in the bulk, due to the limitation of nontransparency of pore wall, especially hydration processes which occur on the surface of the pore wall. Because of these issues, visual and direct study of hydrate growth behavior in pore-sized spaces is very challenging.

In the present study, a self-made transparent perfluoroalkoxy ethylene (PFA) tube is employed to investigate overall growth processes and kinetics of TBAB hydrate, where a $40 \mathrm{wt} \%$ TBAB solution is injected, which fits mostly the TBAB related application systems. The corresponding phase equilibrium temperature of $40 \mathrm{wt} \% \mathrm{TBAB}$ solution is $12{ }^{\circ} \mathrm{C}$. A microscopic hydration system is introduced to gain insights into the growth process and growth kinetics of TBAB hydrate formation in confined pore-sized spaces. A growth model is proposed for the mechanism of the growth process. Based on the growth kinetics and the Arrhenius equation, activation energy is calculated here for the formation process. Also formation properties of TBAB semi-clathrate hydrates, namely formation morphology and nucleation time are obtained.

\section{Materials and methods}

\subsection{Materials}

TBAB (99 \% pure) from Kermel Chemical Reagent Co., Ltd was dissolved in distilled water so that the mass fraction in TBAB $n \mathrm{H}_{2} \mathrm{O}$ corresponding to a hydration number $n=26^{34,35}$. Anhydrous ethanol was provided by Nanjing Chemical Reagent Co., Ltd to function as cooling medium.

\subsection{Nucleation time measurement}

The common method to obtain nucleation time is to monitor the variation of temperature and pressure in the system. In the case where an extremely small amount of hydrate is formed, the hydration heat produced is too small to cause a change on the transducer and no temperature change can be observed. Another method of determining nucleation time is by visual inspection. A typical temperature profile in the low-temperature cell is shown in Figure 1. The photograph in Figure 1 shows the initial formation of TBAB hydrate. It can be 
seen that the temperature of the cell decreased from ambient temperature of around $29{ }^{\circ} \mathrm{C}$ to the set-point of $-5.5^{\circ} \mathrm{C}$ within a time of $t_{c}$ (about 35 minutes). The corresponding phase equilibrium temperature of $40 \mathrm{wt} \%$ TBAB solution is $12{ }^{\circ} \mathrm{C}^{14}$. At time of $t_{d}$ (60 minutes). TBAB crystal was first observed by the microscope. The nucleation $t_{i}$ is defined as the time interval between $t_{d}$ and $t_{c}$, i.e.:

$$
t_{i}=t_{d}-t_{c}
$$

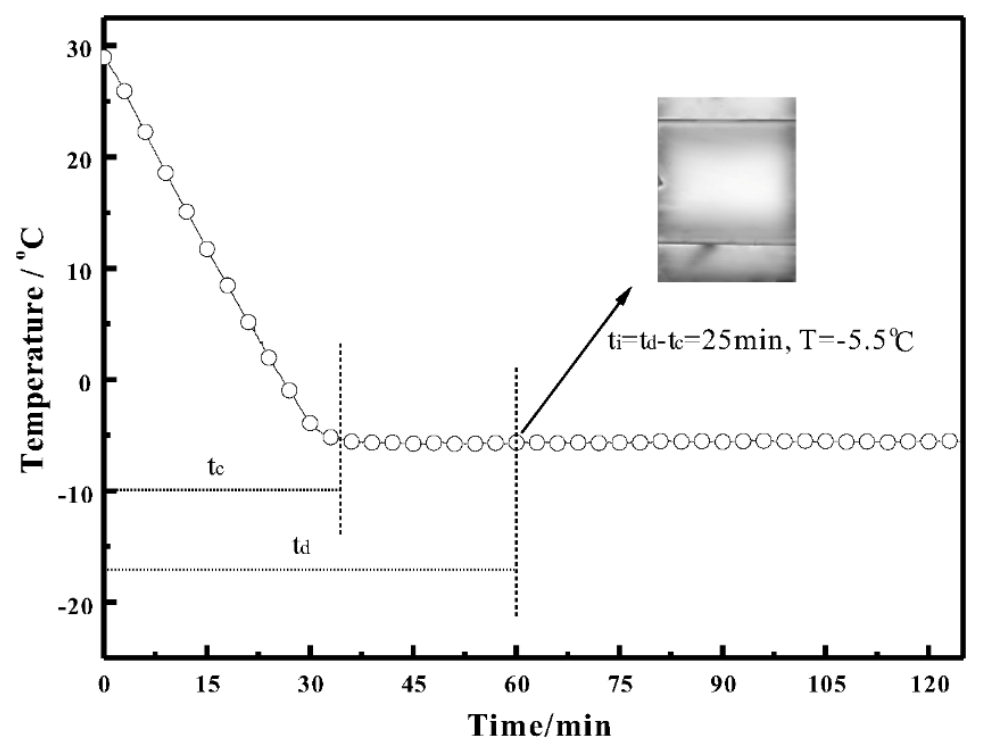

Figure 1. A typical temperature profile of the low-temperature cell and the initial formation of $40 \mathrm{wt} \%$ TBAB hydrate $\left(T=-5.5{ }^{\circ} \mathrm{C}\right)$.

\subsection{Kinetic measurement and apparatus}

Figure 2 shows schematic diagram of microscopic imaging and data logger system employed in the study, mainly consisting of an inverted light microscope (Carl Zeiss Axio Observer A1), a programmed thermostatic bath (Huber Minisbat $240 \mathrm{Cl}$ ), a low-temperature cell and a imaging and data logger.

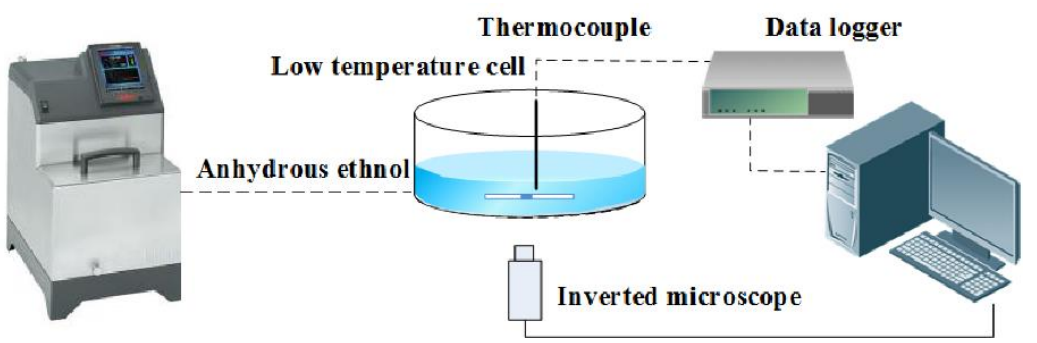

Figure 2. Schematic diagram of microscopic imaging and data logger system.

A piece of transparent PFA tube with inner diameter $580 \mu \mathrm{m}$ is placed into a low-temperature cell $\left(\Phi 50 \times 30 \mathrm{~mm}^{2}\right.$, made of stainless steel $)$. TBAB solution is injected inside the transparent PFA tube with length of around $17 \mathrm{~mm}$ (Figure 3). 
The inverted light microscope is employed to observe the growth process and measure the kinetics combined with an imaging unit (Imaging Micro Publisher 5.0RTV). The low-temperature cell is placed under the microscope and filled with anhydrous ethanol to ensure a stable temperature environment for the hydrate to form in the tube. The temperature of the cell is recorded by a thermocouple and a corresponding data logger. A schematic representation of the formation process and kinetic measurements of TBAB hydrate used in the present study showed in Figure 4.

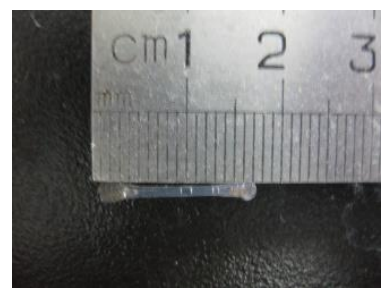

Figure 3. PFA tube sealed with TBAB solution.

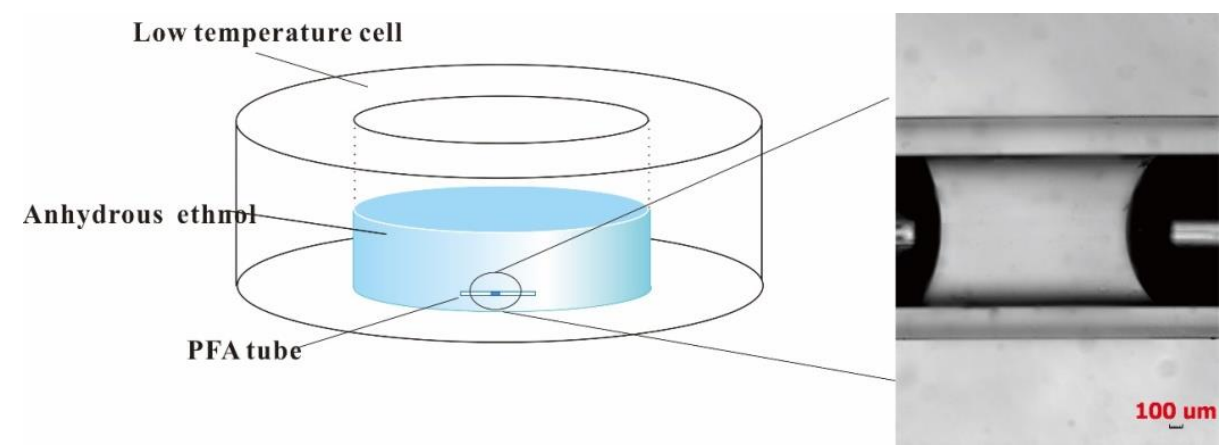

Figure 4. Experimental setup for TBAB hydrate formation observation, with a zoomed-in view of the PFA tube $(\times 50)$.

The space for crystal growth is confined, and only a cross-section of the hydrate is observed by the microscope. When the crystal is originally formed, it grows in all three dimensions. When the crystal meets the tube wall or another crystal, the growth in that direction stops. Hence, a linear growth rate is represented by the crystal surface moving in the direction from the crystal core to the furthest point of the solution in the microscopic view, which is vertical to the face of the crystal measured. Figure 5 shows a typical crystal growth process. $\mathrm{P}_{c}$ is the core of the crystal, and $\mathrm{P}_{\mathrm{f}}$ is the furthest point in the solution relative to $\mathrm{P}_{\mathrm{c}}$. At time $t_{i}$, the distance between $\mathrm{P}_{\mathrm{c}}$ and the crystal surface $\mathrm{S}_{\mathrm{i}}$ in the direction of $\mathrm{P}_{\mathrm{c}}-\mathrm{P}_{\mathrm{f}}$ is $l_{i}$. Hence, the linear growth rate can be calculated by

$$
\frac{d l}{d t}=\frac{l_{i+1}-l_{i}}{t_{i+1}-t_{i}}
$$



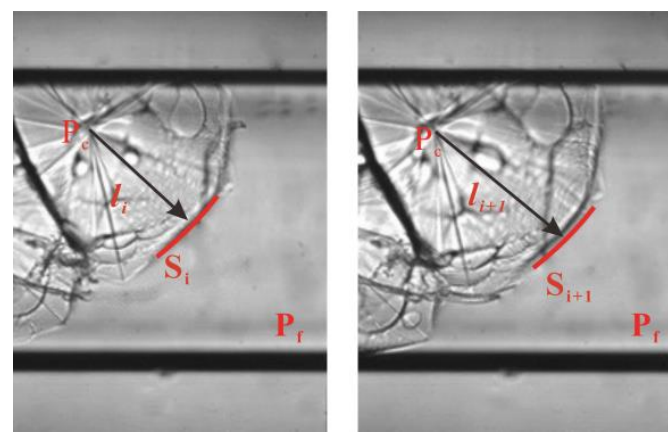

Figure 5. Schematic for the measurement of variation of TBAB hydrate linear growth rate.

\subsection{Experimental procedure}

The $40 \mathrm{wt} \%$ TBAB solution (about $0.3 \mu \mathrm{L}$ ) is injected into the $580 \mu \mathrm{m}$ diameter tube via a micro-injector. The injected liquid is placed under the microscope field of view. Both ends of the $580 \mu \mathrm{m}$ diameter tube are sealed. The tube of TBAB solution is then placed into the low-temperature cell and the microscope aperture is adjusted to give an appropriate brightness in the view. The low-temperature cell is maintained at $29{ }^{\circ} \mathrm{C}$ for $1 \mathrm{~h}$ to eliminate the so-called "memory effect"36-38 of TBAB hydrate, and then decreased to the desired temperature and maintained until the observation ends. The video camera is started and records the hydrate formation process until the hydrate growth ends. The data of temperature and time are acquired by a data logger. Afterwards, a Raman spectroscopy device is employed to identify and analyze the TBAB hydrates in the tube.

\subsection{Raman spectroscopy measurement}

To confirm that the crystal in the transparent tube is TBAB hydrate, Raman spectroscopy (Renishaw inVia-Reflex) is used. During the measurement, while the tube sealed with $40 \mathrm{wt} \%$ TBAB solution is placed into the cooling cell, its temperature is set to the experimental temperature. The temperature is set to decrease at a rate of around $10{ }^{\circ} \mathrm{C} / \mathrm{min}$. After TBAB hydrate is observed to generate in tube through microscope, Raman spectroscopy test is started conducting. The light is provided by a $532 \mathrm{~nm}$ DPSS laser with $50 \mathrm{~mW}$ power, and the scan is performed from $2800 \mathrm{~cm}^{-1}$ to $3700 \mathrm{~cm}^{-1}$ for $10 \mathrm{~s}$ with a band resolution of $0.5 \mathrm{~cm}^{-1}$.

\section{Results and discussion}

\subsection{Raman spectroscopy}


Since the TBAB crystal is formed in water at temperatures below $0{ }^{\circ} \mathrm{C}$, it is necessary to confirm the solid formed in tube is TBAB hydrate rather than simply ice. Raman spectroscopy is an effective method to provide information on structure, occupancy, composition of hydrate and molecule dynamics. Figure 6 shows the Raman spectra of $40 \mathrm{wt} \%$ TBAB solution at $26^{\circ} \mathrm{C}$ and TBAB hydrate at $-5.5{ }^{\circ} \mathrm{C}$ in the range $2800 \mathrm{~cm}^{-1}$ to $3700 \mathrm{~cm}^{-1}$. It can be seen that the peak bands between $2850 \mathrm{~cm}^{-1}$ and $3050 \mathrm{~cm}^{-1}$ are typical for $\mathrm{TBAB}^{39}$. For the TBAB aqueous solution, the widths of the TBAB characteristic peaks are relatively wide and overlap with each other, but for the hydrate sample, the signal peaks are sharp and of isolated ${ }^{40}$. The range shows the symmetric and asymmetric stretching vibrations of $-\mathrm{CH}_{3}$ and $-\mathrm{CH}_{2}$ - in $\mathrm{TBAB}^{41,42}$. The broad peak from 3100 $\mathrm{cm}^{-1}$ to $3500 \mathrm{~cm}^{-1}$ corresponds to $\mathrm{O}-\mathrm{H}$ vibration of water located next to the TBAB peak. Hashimoto et $\mathrm{al}^{43}$ reported that the characteristic peaks of TBAB constitute strong evidence for this study. Formation of TBAB hydrate is thus confirmed for $T=-5.5^{\circ} \mathrm{C}$, as well as for other temperatures, whose Raman spectra are not presented here.

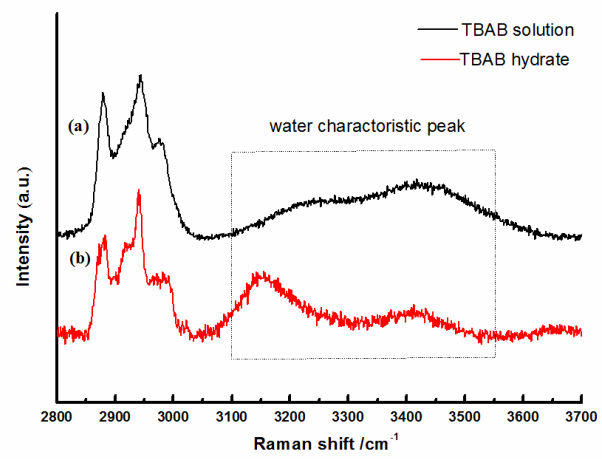

Figure 6. Raman spectra of (a) TBAB solution and (b) TBAB hydrate generated at $40 \mathrm{wt} \% \mathrm{TBAB}$ solution in range of $2800-3700 \mathrm{~cm}^{-1}$.

\subsection{Nucleation time}

The nucleation time is experimentally accessible and contains valuable information about the dynamics of new phase nucleation and/or growth ${ }^{44}$. Nucleation times for the TBAB solution are measured by the method described by Equation (1) for $T=-9.7^{\circ} \mathrm{C},-8.8^{\circ} \mathrm{C},-7.8^{\circ} \mathrm{C},-6.5^{\circ} \mathrm{C}$ and $-5.5^{\circ} \mathrm{C}$ at atmospheric pressure, respectively. Corresponding subcooling degrees are $21.7{ }^{\circ} \mathrm{C}, 20.8^{\circ} \mathrm{C}$, $19.8^{\circ} \mathrm{C}, 18.5^{\circ} \mathrm{C}, 17.5^{\circ} \mathrm{C}$. The results are shown in Figure 7. It can be seen that nucleation time rapidly increases from $9 \mathrm{~min}$ to $25 \mathrm{~min}$ with temperature increasing from $-9.7^{\circ} \mathrm{C}$ to $-5.5^{\circ} \mathrm{C}$. 


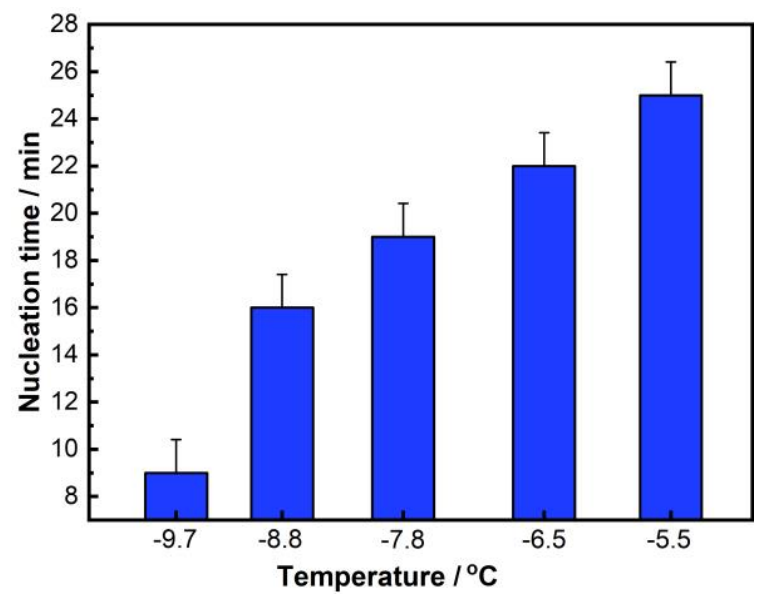

Figure 7. Nucleation time of TBAB hydrate at different experimental temperatures.

The data presented indicate that the nucleation time is strongly dependent on the experimental temperature. The difference between the experimental temperature and the equilibrium hydrate formation temperature provides the driving force for hydrate formation. Under the same system conditions, experiments with a high driving force show that the nucleation time varies exponentially with the size of the driving force ${ }^{45}$.

\subsection{Growth morphologies}

TBAB hydrate generated by $40 \mathrm{wt} \%$ TBAB solution is shown in Figures 8 to 10 , corresponding to the temperatures of $-5.5^{\circ} \mathrm{C},-6.5^{\circ} \mathrm{C},-7.8{ }^{\circ} \mathrm{C},-8.8^{\circ} \mathrm{C}$ and $-9.7{ }^{\circ} \mathrm{C}$, respectively. The results of the camera observations are presented below in order of increasing experimental temperature. 

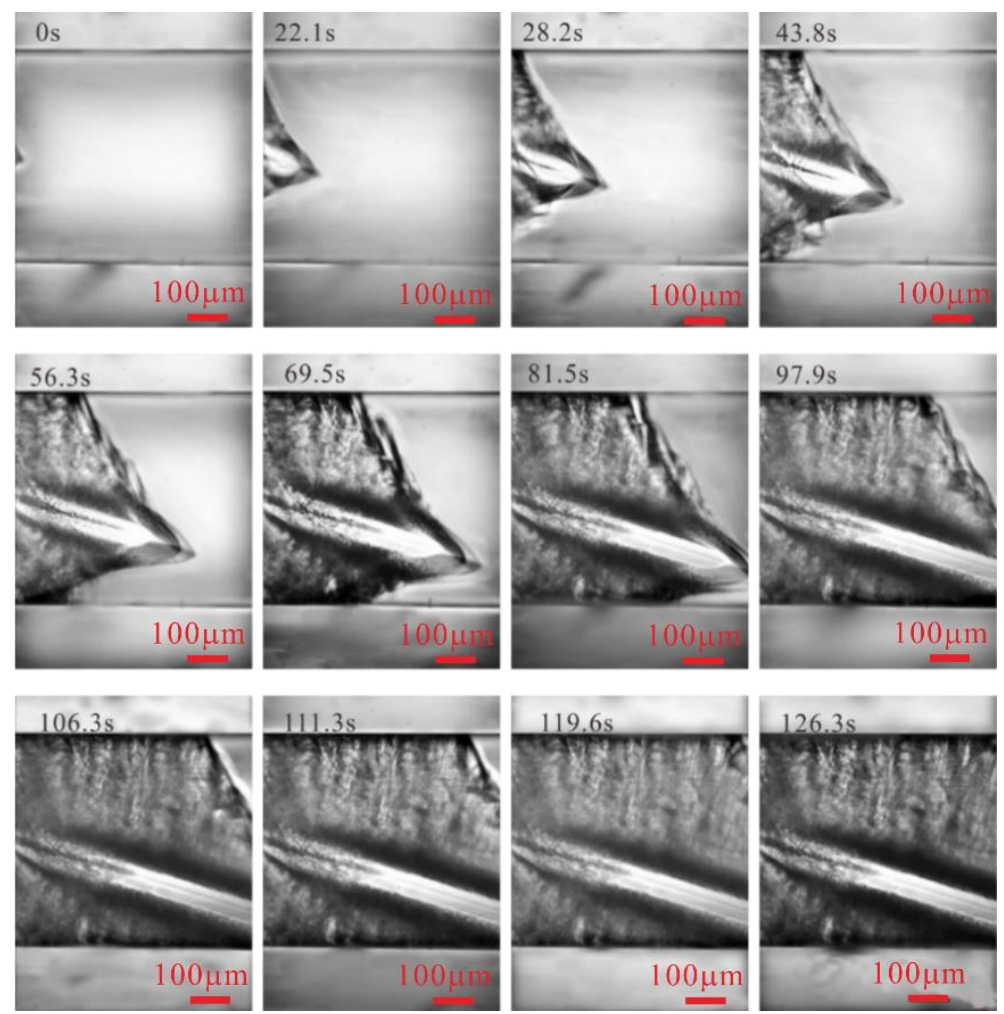

Figure 8. TBAB hydrate formation and growth in PFA tube at $-5.5^{\circ} \mathrm{C}$.

Figure 8 shows a sequence of TBAB hydrate formation and crystal growth in a single position at $-5.5{ }^{\circ} \mathrm{C}$ (a subcooling of $17.5^{\circ} \mathrm{C}$ ). Only the growth phase is observed, meaning that the induction period is completed. TBAB crystals are observed growing gradually from one end of the PFA tube to the other. Hydrate crystals grow in the shape of cylinders with a width of $240 \mu \mathrm{m}$. The contour and brightness from the images confirm that the crystals in the tube center lead the growth with the crystals near the tube wall growing behind the lead crystals. Surface veins on the crystals grows alternatively, interactively and unorderly, which give a reduction on brightness of hydrate. 

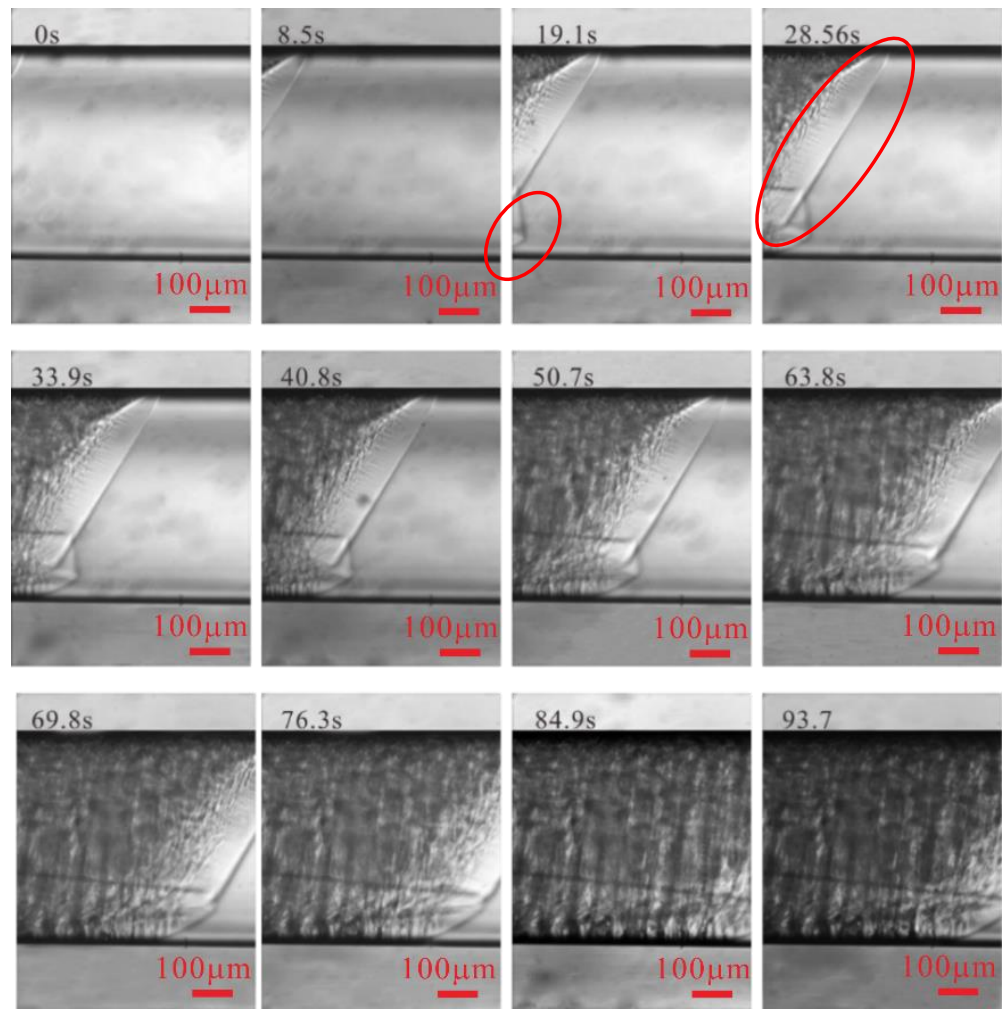

Figure 9. TBAB hydrate formation and growth in PFA tube at $-6.5^{\circ} \mathrm{C}$.

Figure 9 presents the $\mathrm{TBAB}$ hydrate formation and growth at $-6.5^{\circ} \mathrm{C}$. At $0 \mathrm{~s}$, the crystal in columnar is formed firstly in the boundary of view and near the wall of tube. It appears in width of $570 \mu \mathrm{m}$ after $28.5 \mathrm{~s}$ seen from red cycle. After $19.1 \mathrm{~s}$, another crystal at $138 \mu \mathrm{m}$ is formed at a second site. Veins on the crystals are more regular and interlaced compared to that under $-5.5^{\circ} \mathrm{C}$, which makes the transmittance of crystals formed at $-6.5^{\circ} \mathrm{C}$ is greater than for those formed at -5.5 ${ }^{\circ} \mathrm{C}$. 

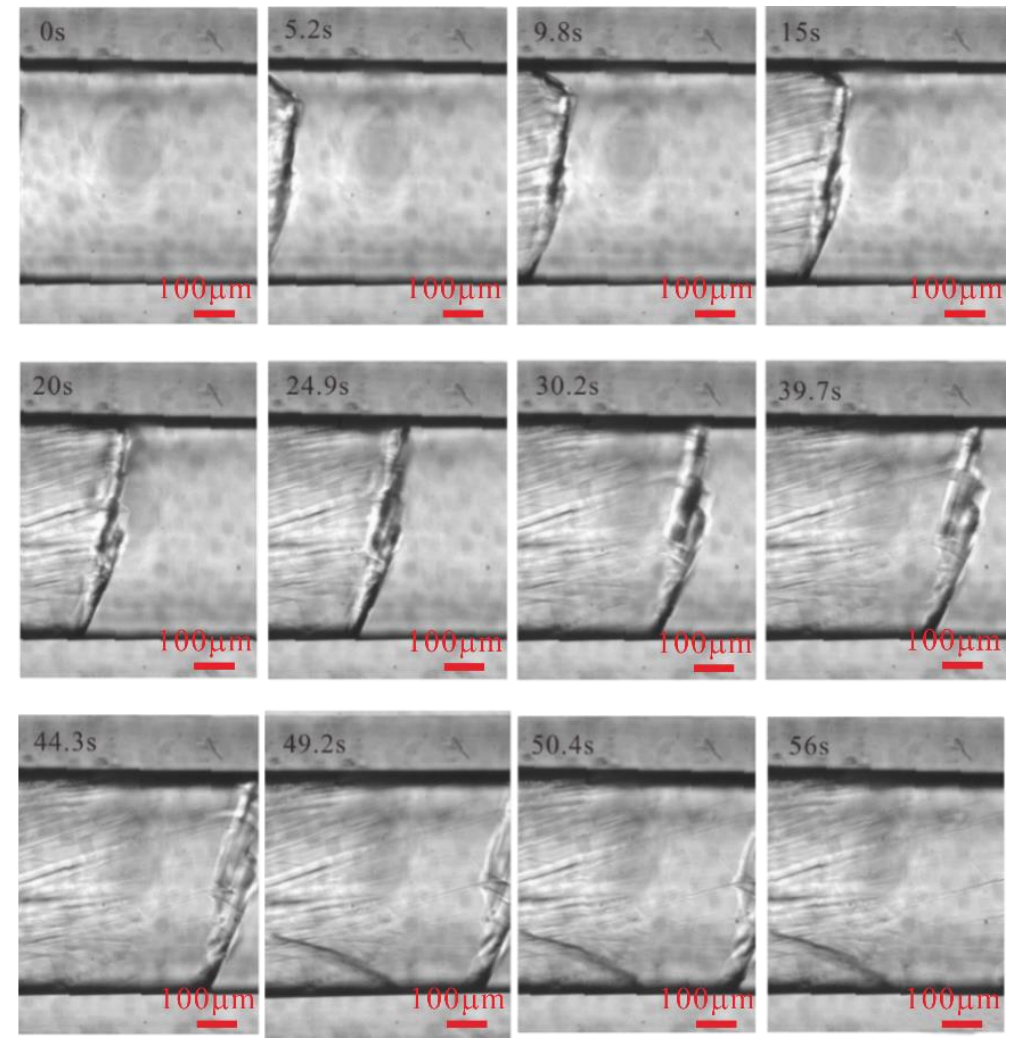

Figure 10. Growth process of TBAB hydrate in PFA tube at $-7.8^{\circ} \mathrm{C}$.

Figure 10 shows the growth of TBAB hydrate, where the images are obtained at $-7.8^{\circ} \mathrm{C}$. The brightness at this temperature is clearly higher than for the higher temperatures. Fewer and more uniform veins appear at the root of the crystal. The first crystal comes into view at $0 \mathrm{~s}$. After $5.2 \mathrm{~s}$, a convex surface moves from the center to the wall in the tube and finally flattens out at $15 \mathrm{~s}$. It is concluded that the hydrate growth surface becomes flat with increasing subcooling (increased driving force). Finally an even lower experimental temperature is used to confirm this conclusion. Experimental temperature has effect on increasing nucleation sites. Crystals generated from more nucleation sites grow uniformly along tube wall. 

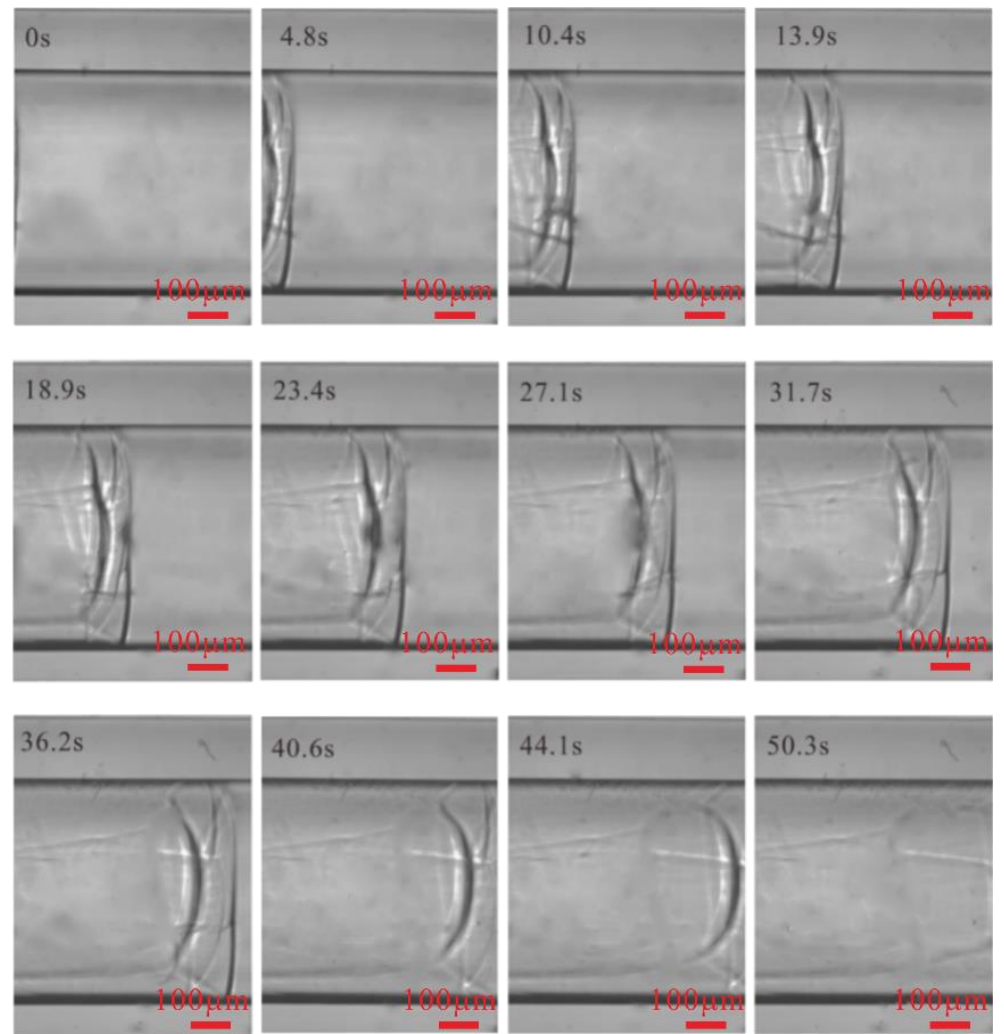

Figure 11. Growth process of TBAB hydrate in PFA tube at $-8.8^{\circ} \mathrm{C}$.

As the temperature decreases, the leading crystals became more obscure. Figure 11 shows that all TBAB crystals grow consistently and the front edge is nearly a smooth surface. In addition, veins on the bulk hydrate disappear at this condition. These morphologies give us information that the tube wall has less effect on the inner crystal growth when the temperature is lower. Furthermore, the number of nucleation sites increase as the temperature gets lower. The hydrate crystals at each nucleation site grow at similar rates, presenting a smooth, nearly planar front edge. 

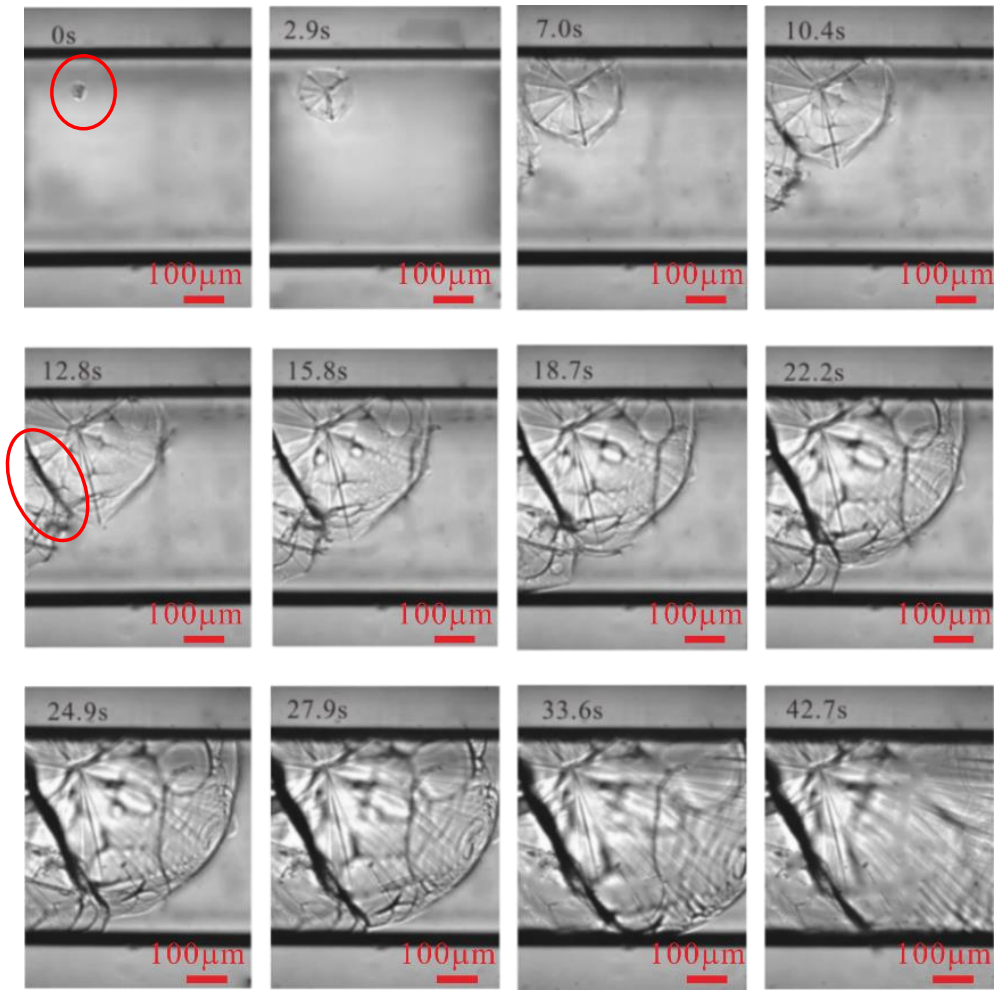

Figure 12. Growth process of TBAB hydrate in PFA tube at $-9.7^{\circ} \mathrm{C}$.

For the experiment carried out at a temperature of $-9.7^{\circ} \mathrm{C}$ (the lowest temperature), TBAB hydrate is initially formed inside the solution at time $t=0 \mathrm{~s}$. The crystals radiate out from the initial crystal. At the same time another crystal may be seen nucleating at the edge of the view, since at time $t=7.0 \mathrm{~s}$, crystals show up at a second site and their boundaries meet. Both crystals continue growing subsequently. At $15.8 \mathrm{~s}$, crystals from the second site meet the tube wall. Growth continues along the tube together with the crystals from the first site. At $27.9 \mathrm{~s}$, the surface of the first crystal reaches the tube wall and the view boundary. A subcooling of $20.8^{\circ} \mathrm{C}$ (the lowest temperature) led to the most crystal growth points in the current study. Since the number of crystal growth points is increasing, the crystals at this temperature present the smoothest surface.

It is interesting to note that with reduction of temperature, the brightness of TBAB hydrate increases. As the light source intensity is maintained constant in all experiments, the different brightness of the photographs taken from the microscopic view may indicate that the crystals formed under different temperatures have different structures, with different light transmittances. Shimada et $\mathrm{al}^{45}$ observed that the TBAB hydrates were columnar and had different morphologies at different temperature. The facets which compose the column changed with temperatures. Some side facets of the column vanished at lower temperatures. In this study, the brightness of the crystals detected from the imaging system indicates that the crystals also have various facets. For these 
experiments, some crystals appears dark (Figure 8, Figure 9), and other crystals appears light (Figure 10-Figure 11). This indicates that there are more facets on the column for the higher temperature range $\left(-5.5^{\circ} \mathrm{C}\right.$ to $\left.-6.5^{\circ} \mathrm{C}\right)$ than for the lower temperature range $-7.8^{\circ} \mathrm{C}$ to $-9.7^{\circ} \mathrm{C}$. The connection between the crystal lightness in the images and the single crystal structure is worthy of further study. Based on heat-transfer considerations in the current study, we concluded that hydrate crystal grows with a convex front edge to enlarge contact area with TBAB solution which is beneficial for heat-transfer at low subcooling $(\Delta T<18.5$ $\left.{ }^{\circ} \mathrm{C}\right)$. At higher subcoolings $\left(18.5^{\circ} \mathrm{C}<\Delta T<21.7^{\circ} \mathrm{C}\right)$, where heat transfer is not an issue, hydrate crystals grow with a flat front surface.

To compare with TBAB hydrate growth in a tube, we also conducted a hydrate growth experiment in bulk, using a cooled reactor made of stainless steel with a silica glass base at a temperature of $-8.8^{\circ} \mathrm{C}$. The images of hydrate morphologies obtained focus on a spot of TBAB solution in the cooled reactor (Figure 13 (a)). Figure 13 (c) shows typical morphologies of TBAB hydrate free-growth formation in TBAB solution from the study of Shimada et $\mathrm{al}^{45}$.

(a)

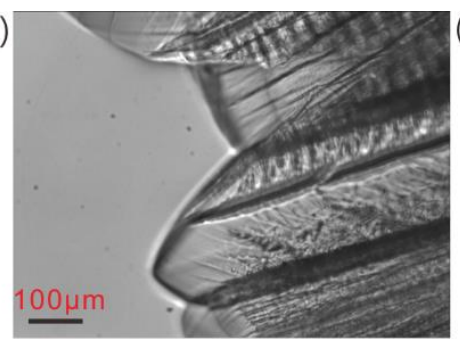

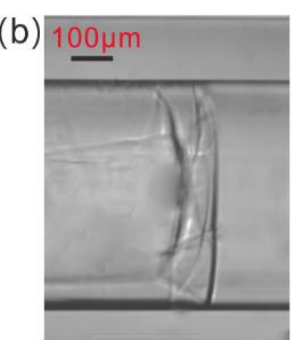

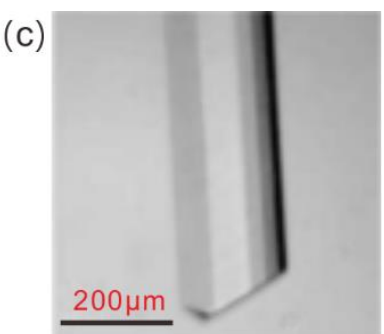

Figure 13. Morphology of TBAB hydrate on flat surface in present study (a), growth in microtube (b) and free-growth forms in bulk solution from literature $(c)^{45}$.

\subsection{Growth kinetics and model of TBAB hydrate formation}

The growth kinetics of TBAB hydrate are influenced by heat transfer, mass transfer and the intrinsic hydrate formation kinetics. From section 3.3 we concluded that morphology is mainly controlled by heat transfer when TBAB hydrate grows in a large scale environment. In the conditions of our experimental setup, heat-transfer effects are eliminated when the small dimensional tube is placed in a bulk cooling system. During the hydrate formation process, TBAB hydrate is formed on the surface of a crystal. A formation kinetics model describing the interface between TBAB hydrate and TBAB solution is thus proposed as follows. Considering the effect of heat transfer, mass transfer and intrinsic hydrate formation kinetic, an expression for growth rate of TBAB hydrate under experimental temperature can be formulated: 


$$
\frac{d n_{s c}}{d t}=K\left(T_{e q}-T_{\exp }\right)
$$

where, $\frac{d n_{s c}}{d t}$ is molar growth rate of TBAB semiclathrate in $\mathrm{mol} / \mathrm{s}$; The temperature of TBAB hydrate facially on the hydrate-solution is equilibrium temperature of TBAB hydrate, $T_{e q}$, Both $T_{e q}$ and constant experimental temperature $T_{\exp }$ are in K. $K$ is growth rate constant in $\mathrm{mol} /(\mathrm{s} \cdot \mathrm{K})$. Since the overall growth resistance is influenced by the three transfer processes, an expression can be written as follows

$$
\frac{1}{K}=\frac{1}{h}+\frac{1}{k}+\frac{1}{\psi k_{a}}
$$

where $h$ is heat transfer rate constant during hydrate formation, $\mathrm{W} / \mathrm{s} ; k$ is mass transfer rate constant, $\mathrm{L} / \mathrm{s} ; k_{a}$ is reaction rate constant in $\mathrm{mol} / \mathrm{s}$. Figure 14 illustrates this model. Figure 14 (a) depicts TBAB hydrate growth in a tube, (b) is an enlarged picture of the interface between TBAB hydrate and TBAB solution. At constant experimental temperature $T_{\exp }$, semiclathrate hydrate grows forward at thesurface temperature $T_{e q}$. The temperature of TBAB solution is considered to be the same as that of the tube wall and ethanol cooling bath and is fixed at $T_{\text {exp. }}$. Lateral temperatures at the interface between hydrate phase (solid) and residual solution phase (liquid) is $T_{e q}$ and $T_{L}$, respectively.

Formation process

(a)

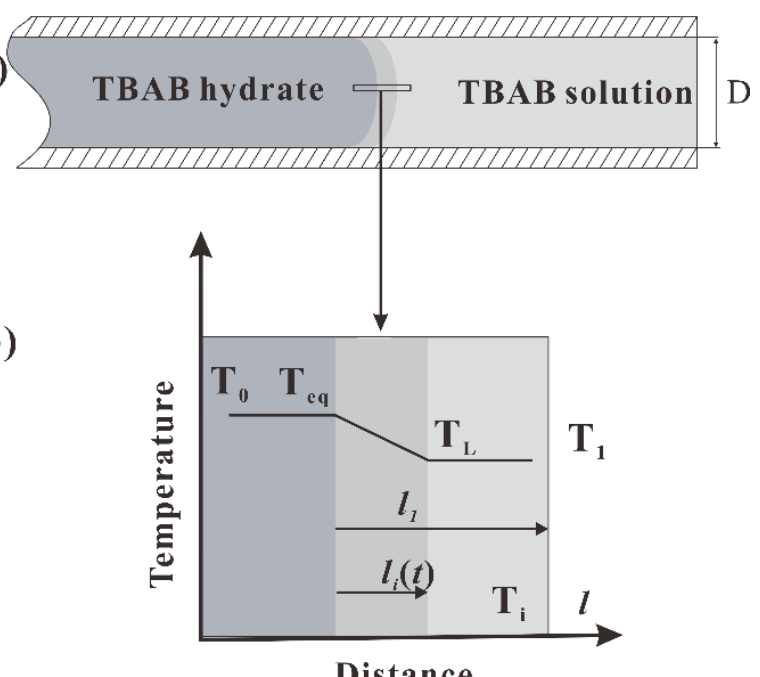

Distance

Figure 14. Conceptual diagram of TBAB hydrate formation based on temperature, (a) Growth process of TBAB hydrate in PFA tube, (b) Interface between TBAB hydrate and TBAB solution.

The kinetic model is based on the following consumptions: (1) Density of TBAB hydrate is constant with time; (2) Growth volume of hydrate in the PFA 
tube is equivalent to that of a cylinder; (3) In the small space, all crystals are considered to have the same, constant growth rate. The TBAB hydrate growth rate can thus be expressed as:

$$
\frac{d n_{s c}}{d t}=\frac{\rho_{\mathrm{SC}} \pi R_{e}^{2}}{M_{S C}} \cdot \frac{d L}{d t}=\frac{\rho_{\mathrm{SC}} \pi D_{e}^{2}}{4 M_{S C}} \cdot \frac{d l}{d t}
$$

where, $\rho_{s c}$ is the density of TBAB hydrate, $\mathrm{kg} / \mathrm{m}^{3} ; M_{s c}$ is molecular molar mass of TBAB hydrate in $\mathrm{g} / \mathrm{mol} ; D_{\mathrm{e}}$ can be approximated by the diameter of cylindrical TBAB hydrate growth in PFA tube in $\mathrm{m} ; \frac{d l}{d t}$ is the face growth rate of TBAB hydrate, $\mathrm{m} / \mathrm{s}$. The TBAB hydrate growth rate can then be expressed as:

$$
\frac{d l}{d t}=K\left(T_{e q}-T_{\text {exp }}\right) \cdot \frac{4 M_{S C}}{\rho_{S C} \pi\left(D_{e}\right)^{2}}
$$

For the sake of simplicity, it is assumed that the thermo-physical properties of TBAB hydrate $\left(h_{\mathrm{sc}}, k_{\mathrm{sc}}, 0<l<l_{\mathrm{i}}(t)\right)$ and TBAB solution $\left(h_{\mathrm{L}}, k_{\mathrm{L}}, l_{\mathrm{i}}(t)<l<l_{1}\right)$ are constants. For a cylindrical geometry we have

$$
\begin{aligned}
& \frac{\partial^{2} T_{e q}}{\partial l^{2}}=\frac{1}{h_{s c}} \cdot \frac{\partial T_{e q}}{\partial t}\left(0<l<l_{i}(t)\right) \quad(\text { TBAB hydrate }) \\
& \frac{\partial^{2} T_{L}}{\partial l^{2}}=\frac{1}{h_{L}} \cdot \frac{\partial T_{L}}{\partial t}\left(l_{i}(t)<l<l_{1}\right) \quad \text { (TBAB solution) }
\end{aligned}
$$

where $h_{s c}$ and $h_{\mathrm{L}}$ are thermal diffusion coefficients of TBAB hydrate and TBAB solution, respectively in eqn. (7) and (8) and $l_{i}(t)$ is the position of the interface with time. The overall energy equation at the interface is given by

$$
\rho_{s c} \lambda \frac{d l}{d t}=h_{s c} \frac{\partial T_{s c}}{\partial l}\left(l_{i}, t\right)+h_{L} \frac{\partial T_{L}}{\partial l}\left(l_{i}, t\right)
$$

where $\rho_{s c}$ and $\lambda$ are density and heat of TBAB hydrate formation, respectively. Finally, the control functions can be written in dimensionless form:

$$
\begin{aligned}
& \frac{\partial^{2} \theta_{s c}}{\partial L^{2}}=S t \frac{\partial \theta_{s c}}{\partial t}\left(0<L<L_{i}(\tau)\right) \\
& \frac{\partial^{2} \theta_{L}}{\partial L^{2}}=S t \frac{h_{s c}}{\alpha_{L}} \frac{\partial \theta_{L}}{\partial t}\left(L_{i}(\tau)<L<1\right)
\end{aligned}
$$

where $S t$ is Stefan number. Dimensionless variables and parameters are defined by

$$
\theta_{s c}=\frac{T_{s c}-T_{\exp }}{T_{e q}-T_{o}}, \theta_{L}=\frac{T_{L}-T_{i}}{T_{e q}-T_{i}}
$$




$$
L=\frac{l}{l_{1}}, \tau=\frac{S t \cdot h_{s}}{l_{1}^{2}} t, S t=\frac{C p_{s}\left(T_{e q}-T_{\text {exp }}\right)}{\lambda}
$$

where $C_{P_{s}}$ is specific heat capacity of TBAB hydrate. Boundary conditions of eqn.

\section{(10) and (11) are}

$\theta_{s c}(0, \tau)=\theta$

$$
\theta_{L}(1, \tau)=T R=\frac{T_{1}-T_{i}}{T_{e q}-T_{i}}
$$

\section{and original conditions are given by}

$$
\theta_{L}(L, \theta)=\theta
$$

$$
L_{i}(0)=0
$$

Finally, the energy conversation equation is simplified to

$$
\begin{aligned}
& \frac{\partial \theta_{s}\left(L_{i}, \tau\right)}{\partial L}+H \frac{\partial \theta_{L}\left(L_{i}, \tau\right)}{\partial L}=\frac{d L_{i}}{d \tau} \\
& H=\frac{h_{L}\left(T_{i}-T_{e q}\right)}{h_{s c}\left(T_{e q}-T_{o}\right)}
\end{aligned}
$$

Considering the following equation representing solid $\mathrm{TBAB}$ and liquid water to TBAB hydrate as structure $\mathrm{A}$ :

$\mathrm{TBAB}+x \mathrm{H}_{2} \mathrm{O}=\mathrm{TBAB} \cdot x \mathrm{H}_{2} \mathrm{O}$

After TBAB hydrate formation has taken place, the concentration of residual TBAB solution can be obtained based on mass conservation where the initial amounts of TBAB and water are $n_{T B A B, 0}$ and $n_{H_{2} O, 0}$, respectively.

$$
c_{T B A B}=\frac{n_{T B A B, 0}-n_{s c}}{n_{H_{2} O, 0}-x n_{s c}} \cdot \frac{1000}{18}
$$

Figure 15 shows the concentration distribution of TBAB at the interface of the TBAB hydrate-TBAB solution. The growth proceeds under a driving force of concentration gradients between the content of TBAB in solution and in hydrate $(\Delta c)$ at a given $T$. In the small space, all crystals are considered to have the same growth rate. With these assumptions, the intrinsic kinetics of TBAB hydrate formation can be written as: 


$$
\frac{d n_{s c}}{d t}=k\left(c_{T B A B}-c_{0}\right)
$$

where $c_{\mathrm{TBAB}}$ and $c_{0}$ are the concentrations of TBAB at the TBAB solution-hydrate interface and hydrate-TBAB solution interface, respectively in $\mathrm{mol} / \mathrm{L}$.

\section{Formation process}

(a)

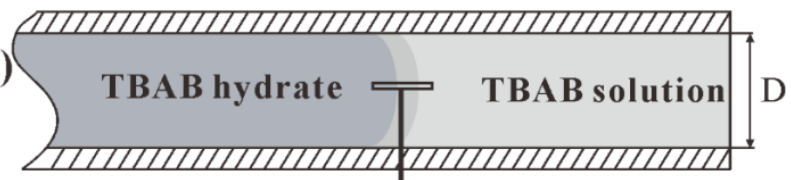

(b)

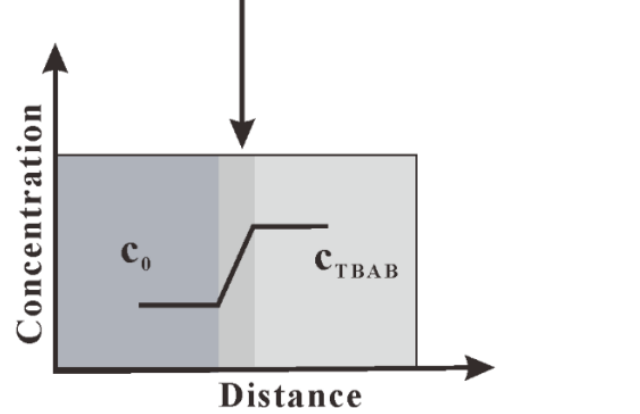

Figure 15. Conceptual model of TBAB hydrate formation based on concentration, (a) Growth process of TBAB hydrate in PFA tube, (b) Magnification of interface of TBAB hydrate and TBAB solution

For reaction kinetic of $\mathrm{TBAB}$ hydrate, growth rate equation can be expressed as:

$\frac{d n_{s c}}{d t}=k_{a} \cdot a_{T B A B}^{m} \cdot a_{H_{2} O}^{n}$

where $a_{T B A B}$ and $a_{\mathrm{H}_{2} \mathrm{O}}$ are activities of TBAB and $\mathrm{H}_{2} \mathrm{O}$ in solution. $m$ and $n$ represent reaction order of $\mathrm{TBAB}$ and $\mathrm{H}_{2} \mathrm{O}$. In the condition of our experimental setup, the heat-transfer effect is eliminated when the small dimensional tube is placed in a bulk cooling system since the heat transfer coefficient approaches infinity $h \rightarrow \infty$. As hydrate formation proceeds, TBAB hydrate continues to form on the surface of the crystal, variations of $K$ under different temperatures can be obtained from experimental data according to equation (5). Crystal growth lengths increasing linearly with time and are summarized in Figure 16. The fitted lines are presented with different colors for each temperature. The results show that the growth increases for decreasing temperature. 


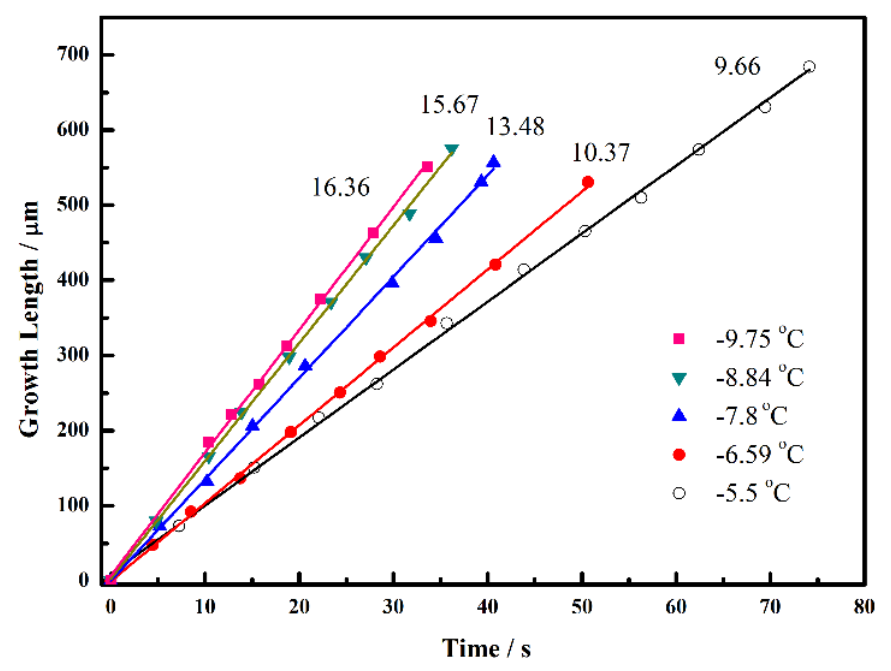

Figure 16. Growth lengths of TBAB hydrate with lapsed time at experimental temperatures $\left(\frac{d l}{d t}\right.$ is the slope of the line and represents the linear growth rate of the hydrate).

The linear growth rates of TBAB hydrate under corresponding experimental conditions and subcooling/driving force are listed in Table 1.

Table 1. Linear growth rates of TBAB hydrate in small spaces with variation of conditions.

\begin{tabular}{ccc}
\hline $\begin{array}{c}\text { Experimental } \\
\text { temperature } T_{\text {exp }} /{ }^{\circ} \mathrm{C}\end{array}$ & Subcooling $\Delta T /{ }^{\circ} \mathrm{C}$ & $\begin{array}{c}\text { Linear growth rate } \\
\frac{d l}{d t} / \mu \mathrm{m} \cdot \mathrm{s}^{-1}\end{array}$ \\
\hline-5.5 & 17.5 & 9.66 \\
-6.5 & 19.5 & 10.37 \\
-7.8 & 19.8 & 13.48 \\
-8.8 & 20.8 & 15.67 \\
-9.7 & 21.7 & 16.36 \\
\hline
\end{tabular}

In Figure 17 shows an Arrhenius plot for the growth rate constant K:

$$
K=K_{0} \cdot e^{-\frac{E_{a}}{R T_{\text {exp }}}}
$$

where $E_{a}$ is activation energy of TBAB hydrate in $\mathrm{J} / \mathrm{mol}$ and $K_{0}$ is pre-exponential factor. $R$ is the universal gas constant. $T$ is absolute temperature $(\mathrm{K})$. From equation (26), the obtained activation energy is $-58.27 \mathrm{~kJ} / \mathrm{mol}$ determined by the solid line in Figure 16, indicating a negative correlation with temperature. 


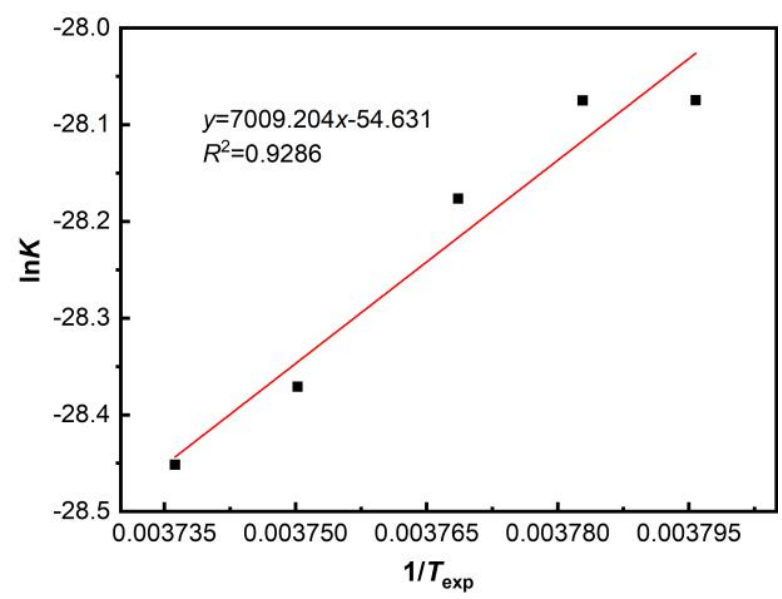

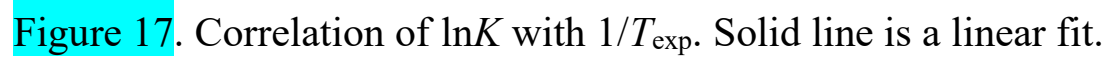

Negative activation energies for TBAB hydrate have not been reported before, although Shimada et $\mathrm{al}^{45}$ observed that TBAB hydrate growth rate has a negative correlation with temperature that is not characterized by its activation energy. Chen et $\mathrm{al}^{46}$ also found that faster rates of methane hydrate were obtained with lower initial temperatures. Nguyen et $\mathrm{al}^{47}$ investigated the effects of temperature on the formation kinetics of difluoromethane hydrate from $\mathrm{CF}_{2} \mathrm{H}_{2}$ gas, and found a positive activation energy of $7.2 \mathrm{~kJ} / \mathrm{mol}$. A negative activation energy occurs when the stability of a state is higher than that of the reactants. A possible explanation is proposed that there exists a state that is metastable compared to the products at a lower energy than the initial status. It is assumed that a large number of empty cages for semiclathrate hydrate appear during the metastable state, which is more stable than randomly distributed $\mathrm{TBA}^{+}, \mathrm{Br}^{-}$and water molecules. This idea is depicted in Figure 18.

TBAB solution

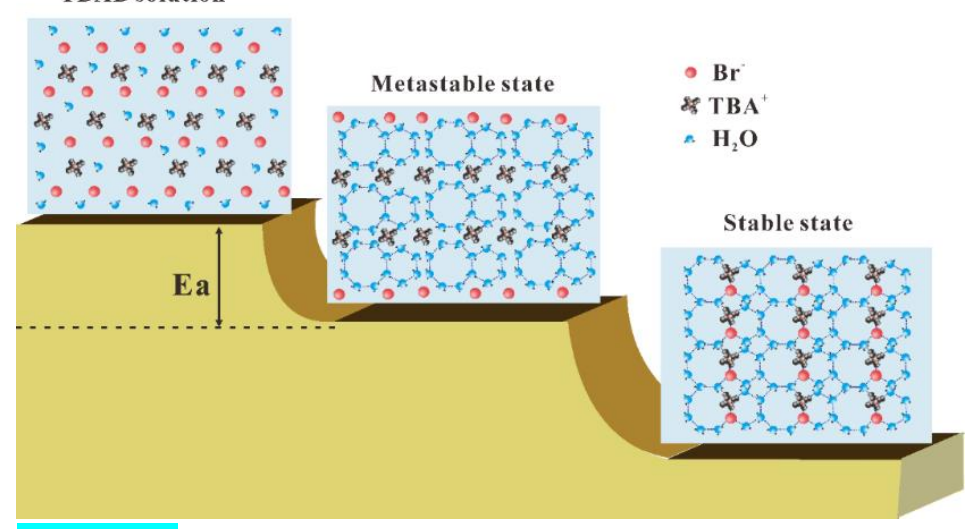

Figure 18. Concept of energy barrier of TBAB hydrate growth process in a tube. 


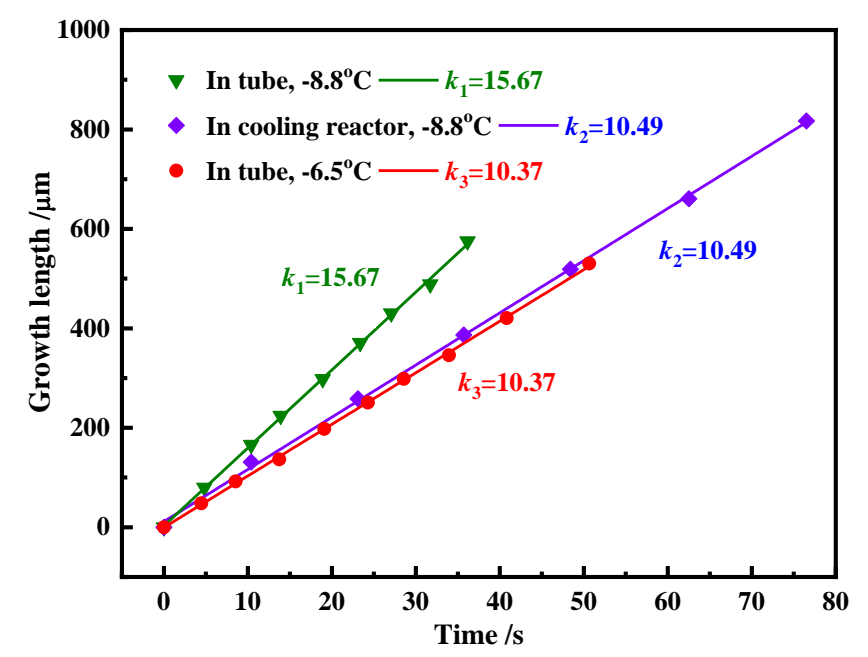

Figure 19. Growth lengths of TBAB hydrate as a function of time in the PFA tube $(\nabla)$, in cooling reactor $(\diamond)$ at $-8.8^{\circ} \mathrm{C}$ and $(O)$ in tube at $-6.5^{\circ} \mathrm{C}$, respectively.

Figure 19 shows the growth length of TBAB hydrate as a function of time at the same temperature of $-8.8{ }^{\circ} \mathrm{C}$ in tube and in a bulk system of a cooling reactor. As can be seen, regression analysis of the series, shown as solid lines, hydrate crystals in cooling reactor grow linearly at a rate of $10.49 \mu \mathrm{m} / \mathrm{s}$ within the observation view. Hydrate grows in the tube with a constant linear rate of 15.67 $\mu \mathrm{m} / \mathrm{s}$, which is faster than in the cooling reactor at the same temperature. The linear growth rate of hydrate crystal in cooling reactor is nearly coincident with that of crystal in the tube at higher temperature. Compared with crystal growth in the bulk system, crystals grow faster in small dimensional tube. These results are in accordance with the $\mathrm{Li}$ et $\mathrm{al}^{48}$. In the bulk system, heat produced by partial hydrate formation contributes to a temperature increase, delaying hydrate formation, while this effect is eliminated in current small dimensional formation crystallizer. Heat generated in tube is transferred to cooling environment immediately upon hydrate formation. The small dimensional tube is thus a more convenient method for hydrate kinetics investigation.

\section{Conclusions}

In this work, a small dimensional tube is utilized to investigate growth kinetics of TBAB hydrate. A growth kinetic model is constructed based on the experimental data.

At the experimental conditions studied, nucleation time increases from $9 \mathrm{~min}$ to $25 \mathrm{~min}$ with temperature increasing from $-9.75^{\circ} \mathrm{C}$ to $-5.5^{\circ} \mathrm{C}$. Crystal linear growth rate decreases from $16.36 \mu \mathrm{m} / \mathrm{s}$ at a temperature of $-9.7^{\circ} \mathrm{C}$ to $9.05 \mu \mathrm{m} / \mathrm{s}$ at a temperature of $-5.5^{\circ} \mathrm{C}$. Morphologies of hydrate under different temperatures changed in the tube. Crystal morphologies give us information that 
hydrate grows in a shape beneficial for heat transfer when the temperature is lower. In addition, the number of nucleation sites increased at lower temperature. Transmittance of TBAB hydrate crystal increases with reduction of temperature. This indicates that some side facets, which compose the column, vanish at lower temperature.

In the current study, the experimental tubes of small dimensional space immersed in a bulk cooling system eliminate the effect of heat-transfer which otherwise makes the investigation of hydrate growth kinetics difficult. Growth kinetic equations and mathematic models are introduced to describe the formation of TBAB hydrate. It is found that the crystallization rate constant of TBAB hydrate formation increases with temperature and that it follows an Arrhenius relationship. Activation energy is calculated to be $-58.26 \mathrm{~kJ} / \mathrm{mol}$. The kinetic models developed in this work may provide assistance in revealing hydrate formation mechanisms.

\section{Acknowledgements}

This work was supported by Chinese National Key Research and Development Programme (2016YFC0304006), National Program on Key Research Project of China (2017YFC0307303-2 and 2017YFC0307302-2), and the National Natural Science Foundation of China (21736005 and 2176005). 


\section{Symbols}

$a_{T B A B}$, activity of TBAB in solution.

$a_{\mathrm{H}_{2} \mathrm{O}}$, activity of water in solution.

$c_{\mathrm{TBAB}}$, concentrations of TBAB at the TBAB solution-hydrate interface, mol/L.

$c_{0}$, concentrations of TBAB at the TBAB hydrate-solution interface, $\mathrm{mol} / \mathrm{L}$.

$C_{P_{s}}$, specific heat capacity of TBAB hydrate.

$\frac{d l}{d t}$, face growth rate of TBAB hydrate crystal, $\mathrm{m} / \mathrm{s}$.

$\frac{d n_{s c}}{d t}$, molar growth rate of TBAB hydrate crystal, mol/s.

$D_{\mathrm{e}}$, diameter of cylindrical TBAB hydrate growth in PFA tube, $\mathrm{m}$.

$E_{a}$, is activation energy of TBAB hydrate, $\mathrm{J} / \mathrm{mol}$.

$h$, heat transfer rate constant, $\mathrm{L} / \mathrm{s}$.

$h_{s c}$, thermal diffusion coefficient of TBAB hydrate.

$h_{\mathrm{L}}$, thermal diffusion coefficient of TBAB solution.

$K$, growth rate constant, $\mathrm{mol} /(\mathrm{s} \cdot \mathrm{K})$.

$k_{a}$, reaction rate constant, $\mathrm{mol} / s$.

$K_{0}$, pre-exponential factor, $\mathrm{mol} /(\mathrm{s} \cdot \mathrm{K})$.

$L_{i}$, at time $t_{i}$, the distance between $\mathrm{P}_{\mathrm{c}}$ and $\mathrm{P}_{\mathrm{f}}$, as shown in Figure $3, \mu \mathrm{m}$.

$M_{s c}$, molecular molar weight of $\mathrm{TBAB} \cdot 26 \mathrm{H}_{2} \mathrm{O}, \mathrm{g} / \mathrm{mol}$.

$m$ and $n$, reaction order of TBAB and $\mathrm{H}_{2} \mathrm{O}$.

$n_{T B A B, 0}$, initial amount of TBAB in solution, mol.

$n_{\mathrm{H}_{2} \mathrm{O}, 0}$, initial amount of water in solution, mol.

$\mathrm{P}_{\mathrm{c}}$, the hydrate growth core as shown in Figure 3.

$\mathrm{P}_{\mathrm{f}}$, the furthest point in the solution relative to $\mathrm{P}_{\mathrm{c}}$, as shown in Figure 3.

$P$, pressure, $\mathrm{Pa}$.

$R$, universal gas constant, $8.314 \mathrm{~J} /(\mathrm{mol} \cdot \mathrm{K})$.

$\mathrm{S}_{\mathrm{i}}$, the hydrate crystal surface, as shown in Figure 3.

St, Stefan number.

$t_{c}$, the period of cooling stage, min.

$t_{d}$, the time from the start of cooling to the appearance of hydrate, min.

$t_{i}$, nucleation time, min.

$T$, temperature, ${ }^{\circ} \mathrm{C}$.

$\Delta T$, subcooling, ${ }^{\circ} \mathrm{C}$. 
$T_{L}$, temperature of solution phase, $\mathrm{K}$.

$T_{\text {eq }}$, equilibrim temperature of TBAB hydrate, $\mathrm{K}$.

Greek letters

$\rho_{s c}$, density of TBAB hydrate, $\mathrm{kg} / \mathrm{m}^{3}$.

$\lambda$, heat of TBAB hydrate formation, $\mathrm{kJ} / \mathrm{kg}$. 


\section{References}

(1) Hashimoto, S.; Sugahara, T.; Moritoki, M.; Sato, H.; Ohgaki, K. Thermodynamic Stability of Hydrogen + Tetra-n-Butyl Ammonium Bromide Mixed Gas Hydrate in Nonstoichiometric Aqueous Solutions. Chem. Eng. Sci. 2008, 63 (4), 1092-1097. https://doi.org/10.1016/J.CES.2007.11.001.

(2) Daraboina, N.; Pachitsas, S.; von Solms, N. Natural Gas Hydrate Formation and Inhibition in Gas/Crude Oil/Aqueous Systems. Fuel 2015, 148, 186-190. https://doi.org/10.1016/J.FUEL.2015.01.103.

(3) Mohebbi, V.; Behbahani, R. M. Experimental Study on Gas Hydrate Formation from Natural Gas Mixture. J. Nat. Gas Sci. Eng. 2014, 18, 47-52. https://doi.org/10.1016/J.JNGSE.2014.01.016.

(4) Daraboina, N.; Pachitsas, S.; von Solms, N. Experimental Validation of Kinetic Inhibitor Strength on Natural Gas Hydrate Nucleation. Fuel 2015, 139, 554-560. https://doi.org/10.1016/J.FUEL.2014.09.013.

(5) Shimada, W.; Shiro, M.; Kondo, H.; Takeya, S.; Oyama, H.; Ebinuma, T.; Narita, H. Tetra-n-Butylammonium Bromide-water (1/38). Acta Crystallogr. Sect. C Cryst. Struct. Commun. 2005, 61 (2), o65-o66.

(6) Kumar, A.; Veluswamy, H. P.; Linga, P.; Kumar, R. Molecular Level Investigations and Stability Analysis of Mixed Methane-Tetrahydrofuran Hydrates: Implications to Energy Storage. Fuel 2019, 236, 1505-1511. https://doi.org/10.1016/J.FUEL.2018.09.126.

(7) Maghsoodloo Babakhani, S.; Bouillot, B.; Ho-Van, S.; Douzet, J.; Herri, J.-M. A Review on Hydrate Composition and Capability of Thermodynamic Modeling to Predict Hydrate Pressure and Composition. Fluid Phase Equilib. 2018, 472, 2238. https://doi.org/10.1016/J.FLUID.2018.05.007.

(8) Zhao, J.; Zhao, Y.; Liang, W.; Song, S.; Gao, Q. Semi-Clathrate Hydrate Process of Methane in Porous Media-Mesoporous Materials of SBA-15. Fuel 2018, 220, 446-452. https://doi.org/10.1016/J.FUEL.2018.01.010.

(9) Darbouret, M.; Cournil, M.; Herri, J.-M. Rheological Study of TBAB Hydrate Slurries as Secondary Two-Phase Refrigerants. Int. J. Refrig. 2005, 28 (5), 663671. https://doi.org/10.1016/J.IJREFRIG.2005.01.002.

(10) Douzet, J.; Kwaterski, M.; Lallemand, A.; Chauvy, F.; Flick, D.; Herri, J.-M. Prototyping of a Real Size Air-Conditioning System Using a Tetra-n-Butylammonium Bromide Semiclathrate Hydrate Slurry as Secondary Two-Phase Refrigerant - Experimental Investigations and Modelling. Int. J. Refrig. 2013, $36 \quad$ (6), 1616-1631. https://doi.org/10.1016/J.IJREFRIG.2013.04.015.

(11) Gholinezhad, J.; Chapoy, A. Separation and Capture of Carbon Dioxide from CO2/H2 Syngas Mixture Using Semi-Clathrate Hydrates. Chem. Eng. Res. Des. 2011, 89 (9), 1747-1751. https://doi.org/10.1016/J.CHERD.2011.03.008.

(12) Ogoshi, H.; Takao, S. Air-Conditioning System Using Clathrate Hydrate Slurry. JFE Tech. Rep 2004, 3, 1-5.

(13) FUKUSHIMA; S. Development of High-Density Cold Latent Heat with 
Clathrate Hydrate. NKK Tech. Rep. 1999, 166, 65-70.

(14) Ma, Z. W.; Zhang, P.; Wang, R. Z.; Furui, S.; Xi, G. N. Forced Flow and Convective Melting Heat Transfer of Clathrate Hydrate Slurry in Tubes. Int. J. Heat Mass Transf. 2010, $53 \quad$ (19-20), 3745-3757. https://doi.org/10.1016/J.IJHEATMASSTRANSFER.2010.04.025.

(15) Shi, X. J.; Zhang, P. A Comparative Study of Different Methods for the Generation of Tetra-n-Butyl Ammonium Bromide Clathrate Hydrate Slurry in a Cold Storage Air-Conditioning System. Appl. Energy 2013, 112, 1393-1402. https://doi.org/10.1016/J.APENERGY.2012.12.021.

(16) Kamata, Y.; Yamakoshi, Y.; Ebinuma, T.; Oyama, H.; Shimada, W.; Narita, H. Hydrogen Sulfide Separation Using Tetra-n-Butyl Ammonium Bromide Semi-Clathrate (TBAB) Hydrate. Energy \& Fuels 2005, 19 (4), 1717-1722. https://doi.org/10.1021/ef0497098.

(17) Renault-Crispo, J.-S.; Servio, P. Methane Gas Hydrate Kinetics with Mixtures of Sodium Dodecyl Sulphate and Tetrabutylammonium Bromide. Can. J. Chem. Eng. 2017, 96 (7), 1620-1626. https://doi.org/10.1002/cjce.23094.

(18) Sfaxi, I. B. A.; Durand, I.; Lugo, R.; Mohammadi, A. H.; Richon, D. Hydrate Phase Equilibria of $\mathrm{CO} 2+\mathrm{N} 2+$ Aqueous Solution of THF, TBAB or TBAF System. Int. J. Greenh. Gas Control 2014, 26, 185-192. https://doi.org/10.1016/J.IJGGC.2014.04.013.

(19) Lin, W.; Delahaye, A.; Fournaison, L. Phase Equilibrium and Dissociation Enthalpy for Semi-Clathrate Hydrate of $\mathrm{CO} 2+\mathrm{TBAB}$. Fluid Phase Equilib. 2008, 264 (1-2), 220-227. https://doi.org/10.1016/J.FLUID.2007.11.020.

(20) Baghban, A.; Ahmadi, M. A.; Pouladi, B.; Amanna, B. Phase Equilibrium Modeling of Semi-Clathrate Hydrates of Seven Commonly Gases in the Presence of TBAB Ionic Liquid Promoter Based on a Low Parameter Connectionist Technique. J. Supercrit. Fluids 2015, 101, 184-192. https://doi.org/10.1016/J.SUPFLU.2015.03.004.

(21) Lee, S.; Lee, Y.; Park, S.; Seo, Y. Phase Equilibria of Semiclathrate Hydrate for Nitrogen in the Presence of Tetra-n-Butylammonium Bromide and Fluoride. $J$. Chem. Eng. Data 2010, 55 (12), 5883-5886. https://doi.org/10.1021/je100886b.

(22) Babu, P.; Chin, W. I.; Kumar, R.; Linga, P. Systematic Evaluation of Tetra-n-Butyl Ammonium Bromide (TBAB) for Carbon Dioxide Capture Employing the Clathrate Process. Ind. Eng. Chem. Res. 2014, 53 (12), 48784887. https://doi.org/10.1021/ie4043714.

(23) Koyanagi, S.; Ohmura, R. Crystal Growth of Ionic Semiclathrate Hydrate Formed in CO2 Gas + Tetrabutylammonium Bromide Aqueous Solution System. Cryst. Growth Des. 2013, 13 (5), 2087-2093. https://doi.org/10.1021/cg4001472.

(24) Veluswamy, H. P.; Yang, T.; Linga, P. Crystal Growth of Hydrogen/Tetra-n-Butylammonium Bromide Semiclathrates Based on Morphology Study. Cryst. Growth Des. 2014, 14 (4), 1950-1960. https://doi.org/10.1021/cg500074c.

(25) Lin, W.; Dalmazzone, D.; Fürst, W.; Delahaye, A.; Fournaison, L.; Clain, P. 
Thermodynamic Studies of CO2 + TBAB + Water System: Experimental Measurements and Correlations. J. Chem. Eng. Data 2013, 58 (8), 2233-2239. https://doi.org/10.1021/je400272k.

(26) Wang, X.; Dennis, M. An Experimental Study on the Formation Behavior of Single and Binary Hydrates of TBAB, TBAF and TBPB for Cold Storage Air Conditioning Applications. Chem. Eng. Sci. 2015, 137, 938-946. https://doi.org/10.1016/J.CES.2015.07.042.

(27) Akiba, H.; Ueno, H.; Ohmura, R. Crystal Growth of Ionic Semiclathrate Hydrate Formed at the Interface between $\mathrm{CO} 2 \mathrm{Gas}$ and Tetra-n-Butylammonium Bromide Aqueous Solution. Cryst. Growth Des. 2015, 15 (8), 3963-3968. https://doi.org/10.1021/acs.cgd.5b00595.

(28) Veluswamy, H. P.; Linga, P. Macroscopic Kinetics of Hydrate Formation of Mixed Hydrates of Hydrogen/Tetrahydrofuran for Hydrogen Storage. Int. J. Hydrogen Energy 2013, $38 \quad$ (11), 4587-4596. https://doi.org/10.1016/J.IJHYDENE.2013.01.123.

(29) Sabil, K. M.; Duarte, A. R. C.; Zevenbergen, J.; Ahmad, M. M.; Yusup, S.; Omar, A. A.; Peters, C. J. Kinetic of Formation for Single Carbon Dioxide and Mixed Carbon Dioxide and Tetrahydrofuran Hydrates in Water and Sodium Chloride Aqueous Solution. Int. J. Greenh. Gas Control 2010, 4 (5), 798-805. https://doi.org/10.1016/J.IJGGC.2010.05.010.

(30) Roosta, H.; Khosharay, S.; Varaminian, F. Experimental Study of Methane Hydrate Formation Kinetics with or without Additives and Modeling Based on Chemical Affinity. Energy Convers. Manag. 2013, 76, 499-505. https://doi.org/10.1016/J.ENCONMAN.2013.05.024.

(31) Gholinezhad, J.; Chapoy, A.; Haghighi, H.; Tohidi, B. Determination of Intrinsic Rate Constant for Hydrate Formation in the Methane-TBAB-water System. In Proceedings of the 7th International Conference on Gas Hydrates; 2011; pp 1721.

(32) Jerbi, S.; Delahaye, A.; Haberschill, P. Characterization of CO2 Hydrate Formation and Dissociation Kinetics in a Flow Loop. Int. J. Refrig. 2010, 33 (8), 1625-1631. https://doi.org/10.1016/J.IJREFRIG.2010.09.003.

(33) Mohammadi, A. H.; Eslamimanesh, A.; Belandria, V.; Richon, D. Phase Equilibria of Semiclathrate Hydrates of $\mathrm{CO} 2, \mathrm{~N} 2, \mathrm{CH} 4$, or $\mathrm{H} 2+$ Tetra-n-Butylammonium Bromide Aqueous Solution. J. Chem. Eng. Data 2011, 56 (10), 3855-3865. https://doi.org/10.1021/je2005159.

(34) Gaponenko, L. A.; Solodovnikov, S. F.; Dyadin, Y. A.; Aladko, L. S.; Polyanskaya, T. M. Crystallographic Study of Tetra-n-Butylammonium Bromide Polyhydrates. J. Struct. Chem. 1984, 25 (1), 157-159.

(35) Dyadin, Y. A.; Udachin, K. A. Clathrate Polyhydrates of Peralkylonium Salts and Their Analogs. J. Struct. Chem. 1987, 28 (3), 394-432.

(36) Ohmura, R.; Ogawa, M.; Yasuoka, K.; Mori, Y. H. Statistical Study of Clathrate-Hydrate Nucleation in a Water/Hydrochlorofluorocarbon System: Search for the Nature of the "Memory Effect." J. Phys. Chem. B 2003, 107 (22), 5289-5293. https://doi.org/10.1021/jp027094e. 
(37) Massah, M.; Sun, D.; Sharifi, H.; Englezos, P. Demonstration of Gas-Hydrate Assisted Carbon Dioxide Storage through Horizontal Injection in Lab-Scale Reservoir. J. Chem. Thermodyn. 2018, 117, 106-112. https://doi.org/10.1016/J.JCT.2017.09.019.

(38) Wang, Z.; Zhang, J.; Chen, L.; Zhao, Y.; Fu, W.; Yu, J.; Sun, B. Modeling of Hydrate Layer Growth in Horizontal Gas-Dominated Pipelines with Free Water. J. Nat. Gas Sci. Eng. 2018, 50, 364-373. https://doi.org/10.1016/J.JNGSE.2017.11.023.

(39) Mohammadi, A. H.; Eslamimanesh, A.; Belandria, V.; Richon, D.; Naidoo, P.; Ramjugernath, D. Phase Equilibrium Measurements for Semi-Clathrate Hydrates of the (CO2 + N2 + Tetra-n-Butylammonium Bromide) Aqueous Solution System. J. Chem. Thermodyn. 2012, 46, 57-61. https://doi.org/10.1016/J.JCT.2011.10.004.

(40) Chen, C.; Li, X.; Chen, Z.; Yan, K.; Zhang, Y.; Xu, C. Raman Spectroscopic Analysis on the Hydrate Formed in the Hydrate-Based Flue Gas Separation Process in Presence of Sulfur Dioxide and Tetra-n-Butyl Ammonium Bromide. Spectrosc. Lett. 2015, 48 (7), 499-505.

(41) Oshima, M.; Shimada, W.; Hashimoto, S.; Tani, A.; Ohgaki, K. Memory Effect on Semi-Clathrate Hydrate Formation: A Case Study of Tetragonal Tetra-n-Butyl Ammonium Bromide Hydrate. Chem. Eng. Sci. 2010, 65 (20), 5442-5446. https://doi.org/10.1016/J.CES.2010.07.019.

(42) Natarajan, V.; Bishnoi, P. R.; Kalogerakis, N. Induction Phenomena in Gas Hydrate Nucleation. Chem. Eng. Sci. 1994, 49 (13), 2075-2087. https://doi.org/10.1016/0009-2509(94)E0026-M.

(43) Hashimoto, S.; Sugahara, T.; Moritoki, M.; Sato, H.; Ohgaki, K. Thermodynamic Stability of Hydrogen + Tetra-n-Butyl Ammonium Bromide Mixed Gas Hydrate in Nonstoichiometric Aqueous Solutions. Chem. Eng. Sci. 2008, 63 (4), 1092-1097. https://doi.org/10.1016/J.CES.2007.11.001.

(44) Kashchiev, D.; Firoozabadi, A. Induction Time in Crystallization of Gas Hydrates. J. Cryst. Growth 2003, $250 \quad$ (3-4), 499-515. https://doi.org/10.1016/S0022-0248(02)02461-2.

(45) Shimada, W.; Ebinuma, T.; Oyama, H.; Kamata, Y.; Narita, H. Free-Growth Forms and Growth Kinetics of Tetra-n-Butyl Ammonium Bromide Semi-Clathrate Hydrate Crystals. J. Cryst. Growth 2005, 274 (1-2), 246-250. https://doi.org/10.1016/J.JCRYSGRO.2004.09.071.

(46) Chen, P.-C.; Huang, W.-L.; Stern, L. A. Methane Hydrate Synthesis from Ice: Influence of Pressurization and Ethanol on Optimizing Formation Rates and Hydrate Yield. Energy \& Fuels 2010, 24 (4), 2390-2403. https://doi.org/10.1021/ef901403r.

(47) Nguyen, M. T.; Amtawong, J.; Smoll, K.; Chanez, A.; Yamano, M.; Dinh, G.-B. H.; Sengupta, S.; Martin, R. W.; Janda, K. C. Gas Flow Rate and Temperature Dependence of the Kinetics of Difluoromethane Clathrate Hydrate Formation from CF2H2 Gas and Ice Particles. J. Phys. Chem. C 2016, 120 (16), 8482-8489. https://doi.org/10.1021/acs.jpcc.6b01294. 
(48) Li, B.; Li, X.-S.; Li, G.; Wang, Y.; Feng, J.-C. Kinetic Behaviors of Methane Hydrate Formation in Porous Media in Different Hydrate Deposits. Ind. Eng. Chem. Res. 2014, 53 (13), 5464-5474. https://doi.org/10.1021/ie500580y.

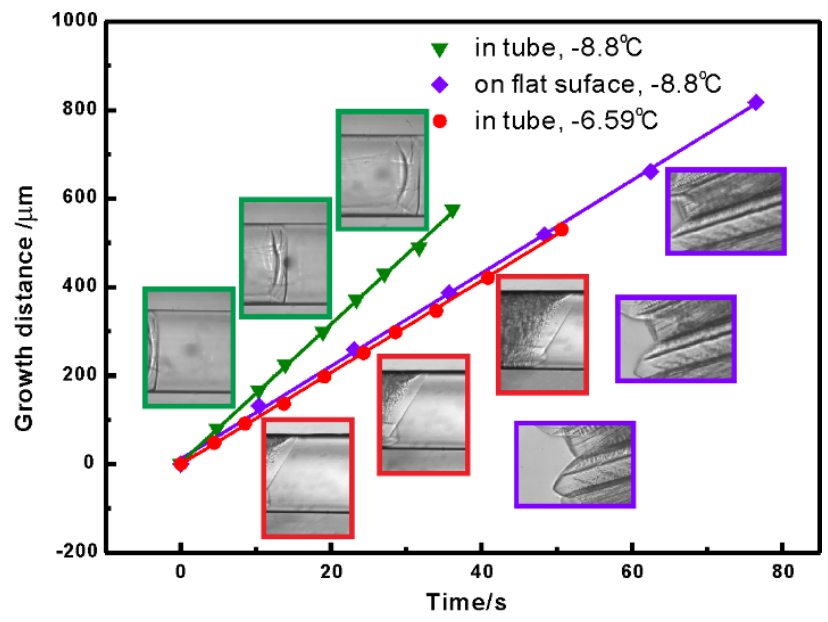

For Table of Contents Only 